\title{
Histórias e memórias de operários têxteis: cenas da cultura fabril e cotidiano em Fernão Velho - AL (Anos 1930 - 1960)
}

Marcelo Góes Tavares*

\section{Abrindo-se aos testemunhos...}

Eram 9h da manhã de uma quinta-feira, dia 23 de janeiro de 2014. Dirigia-me a uma sessão de entrevista como parte do processo de registro de memórias de operários em Alagoas. Cheguei na Rua Dr. Manoel Machado, no 33, no bairro de Fernão Velho, Maceió (AL). Outrora esse bairro foi uma típica vila operária.

O endereço era a residência do operário José Acioly Netto, mais conhecido nessa localidade como Zequinha Moura. Não havia uma campainha. Bati palmas à sua porta e fui recebido pelo próprio operário, um homem de porte físico forte e voz firme, apesar da idade avançada. Nasceu em Fernão Velho em 26 de abril de 1936.

Era filho de Gaudêncio Silva, natural da cidade do Pilar, e Maria José Moura, de Murici. Ambos municípios do interior do estado de Alagoas, e com predominância de atividades econômicas rurais. Seus pais chegaram em Fernão Velho para trabalhar como operários nos idos das primeiras décadas do século XX.

Sua casa era em frente à Fábrica Carmen, uma unidade fabril do ramo têxtil. Tratava-se de uma centenária fábrica em Maceió, uma das mais antigas no Brasil.

Professor de História pela Universidade Federal de Alagoas (UFAL), Mestre pela Universidade de Brasília (UnB) e Doutor pela Universidade Federal de Pernambuco (UFPE). É docente na Universidade Estadual de Alagoas (UNEAL). Atua nas áreas de história, memória, política, trabalho, justiça do trabalho, imagem e ensino de história.E-mail: marce_goes@hotmail.com. 
Fundada em 1857, funcionou até o ano de 2010 (Tavares, 2016). Assim que me recebeu e nos cumprimentamos, Zequinha Moura logo comentou que, naquela hora e daquele local em que nos encontrávamos, ouvia-se o funcionamento das máquinas e da produçáo têxtil. $\mathrm{O}$ som da sirene, quando tocava indicando a alternância entre turnos de trabalho, espalhava-se por toda vila, inclusive adentrando sua residência. Demarcava seu lugar de fala e testemunho, de alguém que durante anos ali trabalhou e trazia consigo toda uma tradição operária. E assim iniciamos nossa conversa, dirigindo-se para o interior da sala na casa de Zequinha Moura, onde por toda aquela manhã registrei suas memórias com uso da metodologia da História Oral.

Seu relato compóe um acervo de nove entrevistas que realizei entre os anos de 2014 e 2015 para a pesquisa cujo resultado culminou na tese "Do tecer da memória, ao tecido da História: operários, trabalho e política na indústrias têxtil em Fernão Velho (Maceió, AL, 1943-1961)" defendida por mim no Programa de Pós-Graduação em História da Universidade Federal de Pernambuco (UFPE) em 2016. As entrevistas priorizaram sujeitos e seus familiares que se enquadravam em uma geração ${ }^{1}$ de Fernão Velho que compartilharam o trabalho fabril e a cultura operária, assim como vivenciaram as diferentes gestóes empresariais pelas quais a vila e respectiva fábrica passou, em especial, os tempos das gestóes das famílias Machado (1891-1938), Leão (1938-1943) e Othon (1943-1996). Os entrevistados, de maneira geral, exerceram o trabalho fabril em Fernão Velho. A partir de suas memórias, deram o testemunho de experiências comuns ou semelhantes, como a migração de seus pais em busca de trabalho e melhores condições de vida, a educação escolar, a iniciação no labor fabril, a conquista de direitos, as festas, o lazer, etc. Além de Zequinha Moura, entrevistei Antônio Cardoso (nascido em 1938), Carlos Caracciolo (nascido em 1946), Darinho (nascido em 1951), Dorival Santos (nascido em 1952), Dona Emília de Souza (nascida em 1935), Idelbrando (nascido em 1932), Valdigleide (nascida em 1973) e Luiz Paulino² (nascido em 1934). Mobilizarei alguns desses personagens neste artigo.

Essas entrevistas foram analisadas em conjunto com diversas fontes documentais, tais como jornais, fotografias, relatórios, processos trabalhistas, entre outras. Nesse sentido, o historiador Antonio Torres Montenegro (2013, p.70) nos sugere que esses entrecruzamentos de fontes náo constituem necessariamente um

1 Para Sirinelli (2002), geração é uma importante peça da engrenagem do tempo, e, portanto, uma noção elástica que compreende diferentes faixas etárias dentro de um mesmo grupo. A referência para identificação de uma geração é o compartilhamento de um acontecimento e/ou seus efeitos.

2 Este último era operário da Fábrica Companhia de Fiação e Tecidos Norte Alagoas, fundada em 1925 no bairro de Saúde em Maceió (AL). 
esforço de produção de prova do real, mas "índices que nos possibilitam construir ou reconstruir significativas experiências historiográficas”. É uma forma de crítica da fonte e do testemunho, levando-nos como diria Paul Ricoeur (2007a), a confrontá-lo com uma série de outros fatores, como a cena vivida, a reconstruçáo do vivido pela memória, suas representaçóes, linguagens e discursos. Possibilitanos um salto das condiçóes formais dos conteúdos e das possibilidades do passado para uma efetiva operaçáo historiográfica, um processo epistemológico que parte da memória declarada, passando pelo arquivo, os testemunhos e documentos, culminando em uma representaçáo historiadora como escrita que ocupa o lugar do passado.

As temporalidades, durante as entrevistas, eram móveis e plurais, assim como os tempos de vida dos operários. Estes rememoravam desde as épocas mais antigas, quando seus pais já trabalhavam na fábrica e lhes contavam suas histórias, até as mais recentes, a exemplo dos momentos de finalização da gestão dos Othon (anos 1990) ou mesmo o fechamento da fábrica em 2010. O tempo, portanto, é em aberto para incursóes, análises e significaçóes quando narrado. Para este artigo, foi definido um recorte temporal que abrangesse desde a década de 1930, quando boa parte dos operários mobilizados nesta escrita nasceram, passaram por suas infâncias, e os idos das décadas de 1950 e 1960, quando em suas juventudes começaram a trabalhar na Fábrica Carmen.

O roteiro das entrevistas suscitou a articulação entre histórias de vida com trajetórias individuais, e temas pré-definidos como o cotidiano, o lazer, a educação, as rotinas de trabalho, os episódios felizes e trágicos que lhes marcaram de forma direta ou indireta, a gestáo da fábrica, o sindicato, o mundo político, entre outros. Além das rotinas de trabalho e práticas culturais, as memórias desses entrevistados trouxeram à tona a disciplina e as resistências, as imbricaçóes entre a vida privada e o trabalho na vila operária, indícios sobre as condiçóes de vida de trabalhadores em Maceió e no Brasil. Permitindo-nos compreender novas formas de expressão da experiência do trabalho, inclusive, aspectos da própria cultura operária.

Para o historiador Mike Savage (2004), a vida operária não se apoia somente no processo de trabalho como único eixo para compreensão do que se designa classe social. Abre-se a possibilidade de análise da insegurança estrutural vivida pelos trabalhadores e que se configura pela retirada dos meios de subsistência destes, constrangendo-os e levando-os ao uso de diferentes táticas para lidar com as incertezas e agruras da vida. Essa insegurança se torna também um elo que une e iguala trabalhadores de diferentes atividades e condiçóes sociais. Destaca ser relevante considerar as estratégias de vida atualizadas, seja nos bairros urbanos, nas vilas operárias e seu cotidiano, ou dentro dos próprios lares dos trabalhadores, seja no processo de trabalho em si. 
Ou noutros termos, faz-se necessário adentrar no mundo da práxis dos trabalhadores, das formas como a vida é vivida por estes (Thompson, 1981). Para o historiador inglês E.P. Thompson (1998), a categoria classe, portanto, não pode ser definida de forma abstrata. É histórica, sua construção se dá no tempo e a partir das açôes e práticas de sujeitos que compartilham interesses, valores, consciência coletiva e práticas sociais comuns.

Ao reconhecermos essas premissas, podemos suscitar diferentes métodos, tornando pertinente o uso de outros paradigmas sobre a História Social do Trabalho, inclusive com contribuições da própria História Oral. O relato oral, para a historiadora Regina Beatriz Guimarães Neto (2012, p. 18) "pode ser lido como um texto em que se inscrevem desejos, normas e regras e, também, apreendem-se fugas; em suma, deve ser trabalhado, tecido e passível de ser lido como um texto articulador de discursos." Nesse sentido, partindo do testemunho de trabalhadores têxteis com seus discursos e representaçôes, proponho-me narrar neste artigo, algumas dimensóes da vida e do cotidiano em Fernão Velho como elementos também constituintes e atualizadores de uma cultura - e experiência - de classe operária.

\section{Da educação escolar ao trabalho operário}

Logo cedo pela manhã, crianças, filhos e filhas de operários percorriam as ruas de Fernão Velho. Algumas mal passavam da altura da cintura de um adulto e, apesar da tranquilidade nas ruas, muitas vezes iam acompanhados por alguém mais velho. Como pequeninos, iam com sono, outros tagarelando, e às vezes até chorando, querendo ficar em casa. Andavam de máos dadas com seu acompanhante, ou não, quando já tinham mais autonomia. Outros, com idade que se aproximava do início da adolescência, juntavam-se em uma turminha fazendo aquela algazarra. Alguns passavam pela Praça Sáo José, com seu coreto e jardim de flores vistosas.

Muitas dessas crianças se destinavam ao Colégio São José, que fora construído pela Fábrica ainda nos tempos dos Machados (1891-1938) e nos tempos dos Othon (1943-1996) e continuou funcionando. Eram ofertadas a alfabetização e as séries iniciais do ensino primário.

Para lá, os operários, outrora estudantes, relatam que caminhavam levando seu material escolar composto por livro, caderno e lápis. Alguns carregavam um lanche preparado pelos pais, mas nem sempre.

Todos vestiam o fardamento da escola. Isso era regra. "Na escola era 100 por cento vestido e com farda completa e composta", afirmou Antônio Cardoso 
(2015). Para todas as crianças eram entreguem o fardamento que deveria ser usado, geralmente feito de tecido branco, mas também usavam calça e saia azul. A padronização facilitava a fiscalização da higiene e permitia distinguir meninos e meninas.

Os meninos, nas memórias de Antônio Cardoso (2015), usavam "calça curta e tamanco para ir para a escola e igreja. [...] O tamanco era muito duro. E durava. Muitas das vezes, eu tinha um cinto velho e cortava as tiras para aproveitar o tamanco". Já as meninas, lembrava que "era uma percatinha baixa, a saia bem comprida, a blusa bem bonita e penteada". Um fardamento que, embora identificasse os alunos, não oferecia conforto, sobretudo para os meninos. Segundo Zequinha Moura (2014), o tamanco era "duro, de pneu, para não se gastar”. O tipo de material usado na confecção do fardamento não era desprovido de uma preocupação empresarial com os custos, devendo ter um uso duradouro.

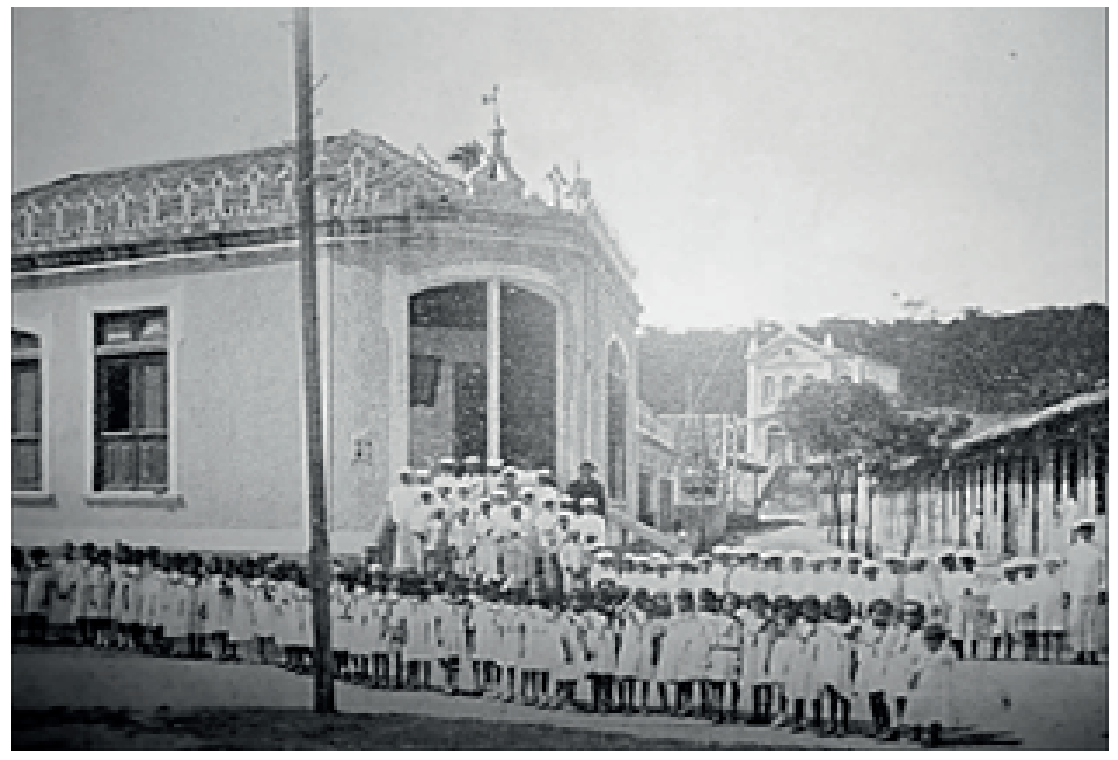

Fotografia 1 - Colégio São José em Fernão Velho Fonte: Marroquim (2000). Acervo da Biblioteca do Instituto Histórico Geográfico de Alagoas (IHGAL).

O colégio parecia ser modesto, com poucas salas de aula, porém suficiente ao número de estudantes. Era de esquina, bem próximo da igreja e da praça central de Fernão Velho. Possuía janelas grandes que ajudavam na iluminação e arejamento. Professores geralmente eram mulheres, havendo homens em menor 
número. Contavam ainda com o Padre Cabral como diretor. As irmãs do padre também foram professoras, lembrou Antônio Cardoso (2015).

Logo ao chegar no colégio, a criançada toda se concentrava em frente à escadaria de acesso, sem poder ainda entrar. Aguardavam do lado de fora o horário para o cumprimento das obrigaçóes cívicas. Meninos e meninas ficavam em pé organizados em fileiras, e, com as professoras e professores de sua turma e demais presentes, cantavam o Hino Nacional, o da Bandeira e, por vezes, o de Alagoas. Formavam um coro com as vozes infantes misturadas às dos adultos educadores na realização daquele ato pedagógico. Quem passava pela rua em frente presenciava tal ato, e, de repente, até poderia juntar-se, ou mesmo relembrar seu tempo de escola. Zequinha Moura (2014) relatou que todos, adultos e crianças, sabiam os hinos.

Depois, poderiam seguir para suas respectivas salas. "A aula começava às 8h até a $1 \mathrm{~h}$ da tarde" (Antônio Cardoso, 2015). As liçóes abordavam saberes de humanidades, ciências e língua pátria. As crianças aprendiam Geografia, História, Matemática e Português.

As meninas, relatou Dona Emília de Souza (2014), também aprendiam bordado, crochê e ponto cruz. Tais saberes eram opcionais aos meninos, embora fossem importantes. Ajudava a desenvolver habilidades manuais que posteriormente poderiam ser úteis aos futuros operários, em especial às mulheres. Lembrou que começou a trabalhar ainda quando era menor de idade. Foi transferida para a seção de urdideira onde exerceu habilidades aprendidas na escola. Fazia as emendas entre um fio e outro, e por aí seguia trabalhando. Ressaltou que era uma garota alta e magra. Tinha excelente trato com a manipulação dos fios de algodão.

A educação física também era praticada no colégio. Veríssimo Ferreira (1997) relatou que havia um campo atrás do colégio, onde hoje existem algumas casas. O professor era Franz Gaspar, oriundo da antiga Tchecoslováquia. Ele morava em Fernão Velho em uma casa na Praça São José. No campo, Veríssimo Ferreira praticou salto em altura, chegando até a se sagrar campeão em uma competição local.

Além das habilidades manuais e físicas, a didática utilizada no ensino de conhecimentos propedêuticos estimulava a memorização, o raciocínio lógico e a perspicácia na mobilização dos saberes, envolvendo, sobretudo, a Matemática e o Português. "Era assim: três vezes oito? Se não sabia, dava à palmatória", relatou Zequinha Moura (2014).

A sanção pedagógica também era mobilizada em momentos de indisciplina e/ou euforia. "Tinha uma professora que tirava o tamanco e batia. Pá, pá, pá... Levanta os pés! E falava para levantar os pés. A preocupação não era com acabar com os tamancos, mas com o piso", lembrou Antônio Cardoso (2015). Ao 
levantarem os pés, os estudantes tornavam-se momentaneamente imóveis em seu lugar, evitando deslocar-se na sala de aula, mantendo-se em sua cadeira perfilada para maior controle e circulaçáo dos educadores entre os educandos. Visava-se à eficiência do aprendizado e disciplina no comportamento, assim como seria exigido na produção fabril.

Segundo Zequinha Moura (2014), embora fosse ofertado a alfabetização, o colégio e os educadores tinham limites na disponibilidade de recursos pedagógicos: "A leitura... dava um livro naquele ano e no outro você ia recordar o livro. Passava dois anos com o mesmo livro." Por outro lado, esses impactos eram minimizados tentando despertar nos alunos a curiosidade e vontade em aprender, superando suas dificuldades na escola com jogos e brincadeiras que se tornavam também parte do cotidiano fora desse cenário instrucional.

Minha vida fora do colégio era estudar vocabulário. Eu gostava de charada, de impugna, de palavras cruzadas, essas coisas... Eu gostava muito. Quando saía do colégio, sentava com uma turma e ia para o impugna. Uma palavra e outra, a turma gostava! A charada então... As brincadeiras eram essas. (José Accioly Netto, 2014).

Pressupunha-se que a educação em Fernão Velho não deveria apenas formar sujeitos dotados de conhecimentos propedêuticos. A presença do padre e outros religiosos no colégio ensejava o ensino religioso entre as crianças. E na Igreja, a catequese. Reforçava-se a docilização moral e dos comportamentos dos infantes através do catecismo, visando também um encaminhamento na fé católica. A própria instituição escolar era nomeada com o nome de um santo católico, São José, também conhecido como santo dos operários. Além desse aspecto subjetivo, a própria igreja se localizava bem próxima ao colégio. As açôes pedagógicas do Padre Cabral com as crianças quase se confundiam nesses dois cenários. Fomentava-se uma simbiose de ensinamentos que deveriam ser levados para a vida e o bem viver como operário.

Visava-se, inclusive, tentar afastar operários de supostos atos e sujeitos subversivos. Em Fernão Velho, o Padre Cabral, que atuou da década de 1940 até final dos anos 1950, advertia e repudiava aqueles que, de algum modo, seja por folia, seja por consciência política, frequentassem comícios de comunistas. ${ }^{3} \mathrm{Nas}$ memórias de Dona Emília de Souza (2014), sua irmã, quando garota, por vezes frequentou alguns atos de comunistas e até mesmo conheceu alguns militantes

Sobre produção social do medo do comunismo na experiência política brasileira durante o Período Democrático (1945-1964), são relevantes os estudos dos historiadores: Porfírio (2009), Rodeghero (2003), e Cavalcanti (2010). 
do credo vermelho que andaram professando sua ideologia por Fernão Velho. E o Padre Cabral indagava negativamente: "Você estava com os comunistas?!?!". Conforme a operária, o pároco não gostava dos comunistas, não se dava com eles. Sua política era a igreja. "Ele tomava conta da igreja e das suas ovelhas!" (Emília de Souza, 2014).

$\mathrm{Na}$ década de 1950, os Othon construíram uma nova escola. Nomearam-na Maria Amália, em homenagem à esposa do velho Othon Lynch Bezerra de Mello. Localiza-se na Vila $\mathrm{ABC}$, que também foi construída nesse mesmo período, quando se ampliou o número de casas para o crescente operariado absorvido pela Fábrica Carmen. A creche, que antes funcionava onde hoje há o prédio do escritório na própria fábrica, foi transferida para outro local, mas continuou sendo ofertada. No Colégio São José, as crianças permaneciam, no máximo, até a idade de 14 anos, ou pouco antes, quando geralmente concluíam o primário. Em Fernão Velho, a fábrica não ofertava os ensinos ginasial e colegial, segundo e terceiro ciclos de formação educacional respectivamente. ${ }^{4}$

Contudo, Zequinha Moura soube aproveitar as oportunidades que the surgiram. Com 14 anos de idade, finalizou seu primeiro ciclo escolar no Colégio São José. Não cessou sua formação, buscou formas alternativas de acesso ao conhecimento, inclusive nos momentos de diversão, quando exercitava a leitura.

Nos dias de feira na praia lagunar em Fernão Velho, geralmente se tinha acesso a folhetos de histórias que remetiam à tradição oral, a exemplo da literatura de cordel. Nesse tipo de literatura abordava-se temas do cotidiano, histórias diversas que oscilavam entre lendas, causos políticos, pelejas de heróis e antiheróis, contos que lembravam cenários rurais, entre tantas outras. Tudo em uma linguagem fácil e acessível. Tanto para os que tinham menores níveis de escolarização e letramento como os que possuíam leitura avançada, ou mesmo os analfabetos que participavam ouvindo as histórias contadas. Realizavam-se sessóes de leitura de histórias capazes de entreter, de tirar risos e gargalhadas, de fazer viajar por meio da imaginação, mas também de ensinar e aprender nos caminhos da informalidade e espontaneidade.

Eu mesmo ouvia muita história de cordel. Sempre aparecia, de fora, nas feiras daqui. E tinha gente para ler à noite nas casas. Não tinha televisão naquela época, rádio era difícil. Então traziam aqueles livros de cordel e começava a falar, ler. E o passatempo era esse (José Accioly Netto, 2014).

4 Na legislação educacional brasileira do fim do século XX, o ensino ginasial correspondia aos quatro últimos do que se nomeia como Ensino Fundamental, enquanto o colegial, ao Ensino Médio. 
Zequinha Moura transformava essas práticas de lazer em oportunidade de aprendizado com a leitura. Desde criança, gostava de praticar seu vocabulário com jogos e palavras cruzadas. Gosto que possivelmente aprendera na escola, entre o querer aprender e a dor da palmatória.

Ainda sem concluir sua instrução escolar, já carregava consigo uma formação diferenciada, além de certa sensibilidade para compreender sobre a situação social de sua família. Relatou que na década de 1950, seu pai, Gaudêncio, já era um homem velho e tivera nove filhos, o que dificultava a manutenção da sobrevivência de sua família. Zequinha Moura, por sua vez, tentava ajudar como podia, pegando um peixe, um siri, o que fosse possível pescar na laguna Mundaú, às margens de Fernão Velho. O que pescava levava para casa, ou por vezes vendia aos passageiros do trem que parava na estaçáo da vila operária. Com a venda, o pouco dinheiro era somado para a aquisição dos víveres necessários na alimentação, mas também lhe servia para pagar a entrada do cinema, onde se divertia assistindo filmes.

Nessa época, a Fábrica Carmen já contratava jovens. Dona Emília de Souza (2014) relatou que recém havia concluído o $4 .^{\circ}$ ano primário, e logo iniciou sua vida no trabalho com 14 anos e meio. Teve a carteira assinada, a carteira de menor. Ganhava metade do salário dos adultos, embora exercesse as mesmas atividades.

Zequinha Moura, mais ou menos com a mesma idade, já nutria o interesse em se tornar operário, até mesmo para ajudar sua família diante da situação que viviam. Seu pai não concordou. Fazia questão de incentivar o estudo dos filhos. Considerava essa idade o tempo para estudar. Mas aos 17 anos, Zequinha Moura procurou o gerente, Seu Carlos, um italiano, para pedir emprego:

Queria trabalhar e fui. O gerente ficava ali dentro no escritório. Passava aqui na porta e me conhecia. Daí eu o procurei. Ele disse: 'o que queres?'. Respondi: 'Seu Carlos, quero trabalhar'. Seu Carlos: 'Por que queres trabalhar?' Disse: 'Porque quero ajudar meu pai!' [...] Daí o gerente pegou um pedaço de jornal e disse: 'Leia aí!' Li o jornal e ele disse: 'Traga o seu registro.' Foi quando tirei o registro e fui trabalhar. Fui trabalhar na Fábrica no dia 12 de fevereiro de 1953. Fui para a tecelagem. (José Accioly Netto, 2014).

No seu relato, destaca que foi no momento em que conseguiu seu primeiro emprego que "tirou registro". Podemos perceber o quanto era representativa a relação entre trabalho e cidadania. $\mathrm{O}$ registro a que ele se refere é o da Certidão de Nascimento e a Carteira de Trabalho e Previdência Social (CTPS). Com esses documentos e a formalização de um emprego, o operário passava a ser beneficiário das leis do trabalho como um direito social. E do mesmo modo, muitos formalizavam sua existência civil com a Certidão de Nascimento. 
A cidadania para esses trabalhadores pautava-se, bastante, no usufruto do que essas leis do trabalho poderiam oferecer, como previdência e assistência social, férias, e posteriormente, o $13 .{ }^{\circ}$ salário, entre outros. Em relaçáo à empresa, também passavam a usufruir de melhor condição de vida, não somente pelo salário que se somaria à renda de suas famílias, mas pela assistência patronal por meio de serviços diversos.

$\mathrm{Na}$ tecelagem, não ficou por muito tempo. Embora muito jovem, e até mesmo inexperiente na produção fabril, chamara a atençáo de seu gerente de seçâo e até mesmo de outros chefes na hierarquia da produção. Não era comum a existência de operários com o nível de letramento de Zequinha Moura, o que lhe rendeu destaque entre os demais colegas de labuta, conforme relatou:

Trabalhei um ano e mais ou menos cinco meses na tecelagem. Daí num dia de sábado chegou um encarregado. Eu estava com um saco com as tramas de tecidos e caneias cheia de linha para abastecer e fazer os tecidos. Eu abastecia aquilo ali para náo faltar. Abastecia todos. E tinha um saco cheio num carrinho. Daí chegou o encarregado e me chamou. 'Deixe esse carro e venha cá. Pegue o saco e entregue a alguém.' E eu... 'Oxente, deixa eu trabalhar!'. E ele: 'Não! Pode entregar. Venha cá!'. (José Accioly Netto, 2014).

O então jovem operário, todo desconfiado com aquela situação, foi ao encarregado sem saber o porquê do chamado. $\mathrm{O}$ encarregado the ordenou que o acompanhasse, e assim o fez, porém, angustiado com o incógnito desenrolar daquela situação. A cada seção pela qual passava, em direção ao escritório, sua angústia aumentava. Especulava em seu íntimo o que iria suceder consigo. "Oxe, o que está havendo?! Será que vou ser indenizado?”, exclamou Zequinha Moura (2014) ao lembrar desse episódio. A indenização representaria a demissão, o que repercutiria na renda de sua família. Além da possível vergonha por ser um adolescente letrado, capaz, e tão cedo dispensado. Seria forçado a sair dali em busca de novo trabalho. Seguiram então e subiram no escritório.

Lá dentro estava o chefe do escritório. Aí o encarregado disse: 'Pronto seu Orlando, o rapaz é este!' Fiquei cismado. E ele disse ao encarregado que podia ir. Fiquei lá. Ele perguntou: 'É o senhor que é seu Zequinha?' Assim mesmo! (José Accioly Netto, 2014).

Era manhã de um sábado. Zequinha Moura havia entrado no turno das 6h, e sairia às $10 \mathrm{~h}$. Porém, Orlando, o gerente, chamou outro contínuo, ordenando-o que ensinasse a Zequinha Moura sobre todos os setores da fábrica. Foi obrigado a permanecer. 
Quando chegou no setor de tecelagem, de onde fora chamado para se apresentar no escritório momentos antes, Zequinha Moura lembrou que foi visto com livros debaixo do braço, provavelmente para registro de produção dos operários e protocolo de documentos. Os operários tecelóes, que nesse momento já estavam curiosos com a razão da súbita e intransigente convocação do jovem para o escritório, indagaram: "O que é isso?" E ele respondeu sorrindo: "Foi lá em cima! Tô lá em cima agora!” (José Accioly Netto, 2014).

Zequinha Moura (2014) relata que contou aos colegas de seção o que sucedera. Chegando ao escritório e tendo sido apresentado a Orlando, este afirmara: “Tenho boas informaçóes suas, viu?!" Mesmo assim, sua angústia e desconfiança nesse momento não haviam sido desfeitas. Não estava claro ainda o que se passava. Até que Orlando afirmara: "Você vai ficar trabalhando aqui, como office boy, contínuo", lembrou.

Tinha sido promovido, apesar de tão pouco tempo e ainda inexperiente como um operário na função de teceláo. Nem sequer conhecia, na prática, todas as rotinas e seçóes da fábrica. À medida que acompanhava o encarregado designado a ensiná-lo, a cada seçáo que chegava, lembrou que era apresentado a todos: "Olhe, esse rapaz aqui é office boy agora." Na sua nova função, tinha de assinar e despachar logo, sem poder demorar em seção alguma.

O jovem operário, então exemplar nos estudos, construiu-se como sujeito letrado e instruído. Em proveito próprio, transformou taticamente a disciplina escolar e comportamental em oportunidade. Tornara-se um funcionário do escritório, conquistando a confiança dos gestores que administravam a fábrica.

Enquanto isso, já passara, em muito, das $10 \mathrm{~h}$. Sua mãe em casa possivelmente o esperava angustiada pela sua chegada. Talvez se perguntando por onde esse jovem andava, se tinha ido, como de costume, para um distante manancial hídrico. "Saía da fábrica com os colegas, passava em casa, dizia que ia ali e voltava já, e ia para o Catolé tomar banho. Olha a distância... Tomava banho e voltava para almoçar e trabalhar de novo. (José Accioly Netto, 2014)" Naquele sábado, o jovem ainda não retornara, e sequer avisou o que se sucedera, aliviando, assim, o coração de sua mãe diante da espera. Mas esse aviso não poderia ter sido dito por ele, já que estava ocupado em aprender sua nova função laboral diante da promoção.

Chegou em casa por volta das $12 \mathrm{~h}$ e pouco. Já era o horário do almoço. E sua mãe: "Onde estava?" Foi então que Zequinha Moura lhe contou. Não estava no Catolé, ainda estava trabalhando porque o tinham promovido para atuar no escritório. Nem seu pai, que já era um contramestre de tecelagem, homem velho, experiente e com cargo de confiança dos gestores, realizou esse feito: trabalhar para o escritório da fábrica! E sua mãe se pôs a chorar de emoção. "Ela chorou que só!", lembrou Zequinha Moura (2014). 
Na tarde desse mesmo sábado, o jovem operário foi ao empório mantido pela fábrica. Lá eram vendidos tecidos, calçados, além de alimentos e outros produtos. Nesse local, já haviam comunicado que o ex-tecelão e agora office boy, passaria por lá. A ele deveriam ser entregues tecidos e dois pares de botas. De lá, foi à alfaiataria, onde foram tomadas todas as medidas de seu corpo para confecção da farda que o destacaria entre os demais trabalhadores. Na segunda-feira seguinte, já vestindo a nova roupa, foi trabalhar.

Depois de certo tempo, conseguiu liberação da fábrica para continuar seus estudos, provavelmente em 1958, quando o Ginásio Santa Luzia, na região do Tabuleiro do Martins, próximo a Fernão Velho, foi aberto. ${ }^{5}$ Era uma escola municipal inaugurada recentemente.

O ginásio funcionava no turno da noite e em condições precárias, à luz de velas e lampióes. Não haviam instalado a luz elétrica no prédio, "o que não motivou desânimo aos educandos" (Ensino, 1958, p. 7), segundo o jornal Correio da Manhã. Na notícia sobre tais condiçóes de ensino, foram também feitas críticas à gestão da Fábrica Carmen, que, pela proximidade com o ginásio que atenderia seus operários, mesmo assim, não cooperou investindo em uma rede elétrica que suprisse a iluminação necessária.

Zequinha Moura teve o apoio de um dos padres que atuaram em Fernão Velho nos estudos para prova de admissão ao Ginásio. Nessa instituiçáo, Zequinha Moura deu prosseguimento à sua formação escolar. Após dois anos, deixou a função de office boy para trabalhar no setor pessoal. Neste, além da melhoria de salário, fora-lhe subjetivamente exigido maior comprometimento com os interesses da fábrica.

\section{Entre a moral e a constituição familiar}

Zequinha Moura (2014) relatou que, então com 26 anos de idade, tinha organizado uma escola de samba. Esta começou a ser bastante demandada no início dos anos 1960. Recebia convites para se apresentar fora de Fernão Velho, em municípios próximos de Maceió. Deslocava-se de trem, ou mesmo de ônibus, para tocar durante festejos, como o carnaval. Nesse período do ano, a sonoridade das músicas tocadas era propícia ao balancê dos corpos, cujas formas e ritmos são capazes de provocar os desejos contidos pela formação cristã.

5 A abertura do Ginásio Santa Luzia foi noticiada no jornal Correio da Manhã, edição de domingo, 16 de março de 1958 . 
Em uma ocasiáo que os integrantes da escola de samba retornaram após se apresentarem, Zequinha Moura logo fez uso de formação moral: "Quando cheguei aqui, coloquei cada um em sua casa, as mocinhas eu entregava aos pais logo, até isso existia naquela época... tinha de entregar uma por uma em sua casa" (José Accioly Netto, 2014).

Tal ato, para além dos cuidados e respeito com as mocinhas, expressava certa preocupação da fábrica e da igreja com a profilaxia dos desejos, do controle dos corpos no intuito de evitar a promiscuidade, contribuindo para o cálculo da natalidade. $\mathrm{O}$ descuido com a sexualidade poderia implicar em uma gravidez inesperada e a constituição de nova família. Para os industriais e os pais dos jovens operários, era uma preocupação relevante diante dos possíveis transtornos por essa situação. As casas pertenciam à Fábrica Carmen (Farias, 2014) e sua disponibilidade se dava de forma gradativa, conforme fossem sendo construídas de acordo com o número de operários, como pode-se observar em relatórios da fábrica. ${ }^{6} \mathrm{O}$ morar era limitado pela disponibilidade de casas e a quantidade de cômodos que estas possuíam.

Era também comum um novo casal, independentemente das circunstâncias da união matrimonial, continuar vinculado à casa de seus pais, habitando todos juntos na mesma residência. Tal fato poderia gerar transtornos para os demais membros, irmãos, irmãs, avós. As habitações eram pequenas e, de certa forma, desconfortáveis para uma família numerosa. Ou por vezes, era comum duas ou mais famílias dividirem a mesma casa.

Lembro-me como hoje, em uma casa na [Rua] Major Prado, tinha seis famílias. Aqui era seis mil funcionários e só tinha 104 casas na época. Seis mil funcionários e a empresa só tinha 104 casas. Então havia casos que na casa morava várias famílias. $\mathrm{Na}$ minha mesmo tinha três famílias. Daqui para ali um quarto e cozinha, daqui para ali outro quarto e família, e assim ia. Um só sanitário, uma lavanderia para todo o povo. Cada um que tirasse a sua roupa no tempo que podia. (Antônio Cardoso, 2015).

Em outras situaçóes, uma nova família poderia ser constituída mantendose na casa onde um operário ou operária, então na ativa na fábrica, já vivia. Seu Idelbrando (2014), operário aposentado, ficou viúvo quando ainda era moço. Afirmou ter casado novamente com outra mulher, filha de operário. Não havia

A ampliação das estruturas e edificações na vila operária pode ser observada nos relatórios da fábrica publicadas no Diário Oficial de Alagoas. Ver: Companhia União Mercantil, 1930; Companhia União Mercantil, 1931 e Companhia União Mercantil, 1940. O documentário Memória da vida e do trabalho (1986) também narra sobre as condições de moradia em Fernão Velho. 
restrição para essa situação, uma vez que não implicava em prejuízo para os patrôes.

Nesse sentido, a felicidade carnal-amorosa dos jovens viventes, que em grande medida expressariam as sensaçóes de seus corpos como singularidade biológica e psíquica, poderia também se tornar objeto de disciplina moral fabril e religiosa, assim como dos próprios pais. $\mathrm{O}$ que coadunava com a sujeição aos valores preconizados pela igreja e sua educação, mas, sobretudo, pela própria gestão dos Othon no exercício de seu biopoder. ${ }^{7}$ Trata-se de mecanismo regulador da fecundidade e procriação, que implicaria também no cuidado com a higiene das famílias, nos cuidados dispensados às crianças, na educação escolar, entre outras que induzem comportamentos vinculados ao habitat desse território fabril.

Por outro lado, toda disciplina ou todo mecanismo regulador deixa suas brechas. Os jovens operários não se furtavam de suas experiências amorosas e prazeres do corpo. Taticamente as transformavam em romance cujas lembranças do passado são relatadas de forma idealizada e, ao mesmo tempo, permitem liçóes para o presente.

Tinha muito namoro. Hoje, acho essas músicas, à minha maneira, é poluição sonora. Não tem poesia. É só pei, pei, pei... Não gosto mesmo! Tem música bonita hoje, com sentimento, poesia, história bonita. Naquela época você namorava com amor. Existia muita música bonita. (José Accioly Netto, 2014).

Ao contrário do "pei, pei, pei" que dita o ritmo de muitas músicas que podem sugerir a promiscuidade e degenerescência, tentava-se, naquela época, atribuir às relaçóes amorosas significados poéticos. Estes eram embalados por músicas como aquelas cantadas por Dalva de Oliveira, muito ouvidas por alguns operários da geração de Zequinha Moura. A poética nessas músicas sugeria a felicidade e a plenitude na união entre dois amantes.

A constituição de novas famílias ocorria por meio de práticas reconhecidas por todos como respeitosa.

Acontece que ela sempre ia olhar a escola e eu não a conhecia. Quando eu pegava o ônibus aqui para ir para o ginásio, ela descia de casa e ia me ver. Ela já me paquerava e eu sem saber. E ela sempre ia olhar a escola de samba e eu não conhecia. Aí quando é um dia que vou para Murici com a

Sobre o biopoder e a disciplina sobre corpos e população, ver: FOUCAULT, Michel. Em defesa da sociedade. Curso no Collége de France (1975-1976). São Paulo: Martins Fontes, 1999. 
escola de samba, e volto, na sede Othon perto da estação tinha um baile de carnaval. Aí fui! [...] Fui para a sede, tava todo mundo brincando e quando cheguei lá, olhei para ela e me despertou a atençấo. Aí a colega dela, que estava mais ela falou: 'que vir para aqui?'. Aí digo, pera aí... tímido, fui por traz do bar, pedi uma dose de conhaque. Tomei, dei três passadas e aí fui. E sai namorando. Até hoje! Maria Quinô Nazário Acioly. Dezembro agora vou fazer 49 anos de casado. 31 de dezembro de 1965 nos casamos. (José Accioly Netto, 2014).

$\mathrm{Na}$ realização do matrimônio, eram atribuídos sentidos de encantamento, com práticas de conquista sem promiscuidade, de realizaçáo das expectativas diante de um amor talvez platônico, aliados a algumas dosagens de timidez e romantismo. Buscava-se afastar a imagem de uma relação voltada aos desejos do corpo e da pele como território do prazer, embora este também pudesse cotidianamente estar presente nas alegrias das núpcias e entre as paredes íntimas dos quartos dos casais que sucediam com seu casamento.

Todos esses sentimentos, tanto os mais castos, quanto os libertinos, são constituintes da formaçáo das famílias operárias. São nutrientes de uma relação amorosamente febril, cujo amor é aquecido por toda a vida, ou mesmo torna possível a transformaçáo do operário em um corpo produtivo disciplinado na realização dos interesses da fábrica, seja na produção, no controle da natalidade ou nos valores familiares.

Do matrimônio de Zequinha Moura, nasceram oito crianças, quatro homens e quatro mulheres. Entre esses, três trabalharam na fábrica, dois como tecelão e uma como liçadora. Com sua família, experiências e sentimentos de classe e cultura operária foram atualizadas.

\section{Pensamentos que ficam para uma história em aberto...}

Os relatos de memórias mobilizados em parte neste artigo expressam múltiplas dimensóes de experiências do trabalho e da vida em uma vila operária. Esclarecese que suas constituiçôes narrativas não configuraram um sequenciamento linear de tempo e acontecimentos. As memórias registradas com uso da metodologia da História Oral são compostas por lembranças que se apresentam de forma fragmentada, mas que evidenciam acontecimentos muitas vezes negligenciados em outras formas de registros e fontes pesquisados. $\mathrm{O}$ que fortalece as relevantes contribuiçóes da História Oral para a reescrita de uma História Social do Trabalho.

Durante as entrevistas, diversos momentos me deparei com silêncios dos 
operários. Embora o esquecimento como uma dimensão da memória possa ser plausível nessas situaçóes, não deve ser necessariamente compreendida como indício de um vazio de memória. Ao contrário, como nos indica Paul Ricoeur (2007b), deve-se perceber nesses casos, um tipo de memória que opera de forma espontânea e inconsciente na ordem do involuntário; daí seu distanciamento da lembrança.

Nesse ensejo, o trabalho de memória e história oral é também uma forma de resistir contra as possibilidades permanentes do esquecimento. E ao mesmo tempo reconhecer que as lembranças dos operários remetem às múltiplas histórias e acontecimentos, "sem distinguir os grandes e os pequenos", o que para Walter Benjamin (1994), no trabalho de história, não pode ser desconsiderado. Apropriamo-nos, então, de um passado que é lembrado e esquecido, tornando-o citável como constituinte de narrativas historiográficas.

Neste artigo, tomou-se como foco narrativo aspectos do cotidiano em Fernão Velho. As memórias de Zequinha Moura, registradas com uso da metodologia da História Oral, ganharam certa centralidade. A partir de suas memórias entrecruzadas com outros testemunhos de operários e fontes, foram analisadas práticas de educação escolar, ensinamentos de teor moral que marcaram a ética e a vida social, o desenvolvimento profissional, permitindo afirmar-se como operário atuando em diversas funçóes dentro da fábrica, e a própria formação familiar.

Nesta última, pode-se ressaltar o quanto é indiciário o processo de atualização dos legados e experiências dos passados das famílias nos presentes de seus filhos e filhas. Zequinha Moura é exemplar. Na medida em que deu continuidade à tradição de trabalho de seu pai como operário, foi além, alcançando funçóes hierarquicamente superiores dentro da fábrica. Das seçôes de produção de tecidos, chegou a atuar no próprio escritório, espaço da administração da Fábrica Carmen. E ao constituir sua própria família, alguns de seus filhos e filhas foram encaminhadas para o trabalho fabril. Trata-se, portanto, de um processo de atualização da experiência operária, reforçando não apenas os legados do passado, mas também laços de pertencimento a uma história, lugar, trabalho e identidade.

Tornam-se práticas e experiências de uma cultura de classe operária evidenciando-se cotidianos, espaços de sociabilidades, educação escolar, festejos, configuraçôes familiares, costumes, açôes religiosas, enfim, um conjunto de práticas culturais dos operários. Estes sujeitos atuaram e testemunharam como protagonistas das suas próprias tramas históricas, (re)significando sua própria existência.

No fim da manhã de 23 de janeiro de 2014, em poucas palavras, Zequinha Moura fez uma síntese de seu sentimento em relaçáo a tudo que vivera em Fernáo Velho e ao longo da vida. 
Meu sentimento hoje, rapaz, vou lhe ser franco, já tive em São Paulo, no Rio... Quando tive lá nesses lugares, e quando vim embora, olhei para traz e disse: 'Aqui não venho mais.' Gosto muito desse lugar [Fernão Velho]. Nasci e me criei aqui. Sei que vou morrer aqui. Gosto demais de Fernáo Velho. Lembro de minha juventude. Me considerava um operário. Toda vida. Nunca mudei de pensamento não. Minha impressão era sempre essa. Era um operário. Sempre fui. Meu pensamento sempre foi esse. (José Accioly Netto, 2014).

Em meio às múltiplas formas de disciplina e resistências, trabalhadores em Fernão Velho se fizeram operários. Zequinha Moura era convicto disso. Afirma nunca ter mudado seu pensamento e sentimento, e pressuponho que se tenha tornado solidário aos seus colegas de produção fabril. Assim como ele, muitos operários que cederam entrevistas usaram do artifício do saudosismo, de sentimentos de vitórias quanto às conquistas de direitos e condições de vida, mas também de denúncia do passado em seus testemunhos. Por fim, confirmou-se o presságio de Zequinha Moura. Faleceu em Fernão Velho em 2014, cinco meses após contar suas memórias mobilizadas em parte nesta narrativa. Restam-nos suas experiências, assim como de outros trabalhadores como legado das lutas e experiências que saltam do passado e permitem que se tornem críveis como histórias e práticas de uma cultura operária.

\section{Referências}

BENJAMIN, Walter. Magia e técnica, arte e politica: ensaios sobre literatura e história da cultura. 3. ed. São Paulo: Brasiliense, 1994. (Obras Escolhidas, v. 1).

CAVALCANTI, Erinaldo Vicente. Relatos do medo: a ameaça comunista em Pernambuco, Garanhuns 1958/1964. Recife: Editora da UFPE, 2010.

COMPANHIA UNIÃO MERCANTIL, Relatório dos negócios sociaes da Companhia União Mercantil, relativos ao anno de 1929, para ser apresentado em Assembléia Geral de Accionistas no dia 17 de março de 1930. Diário Official de Alagoas. Maceió: Governo do Estado de Alagoas, 18 mar. 1930. p. 5-6.

COMPANHIA UNIÃO MERCANTIL. Relatório dos negócios sociaes da Companhia União Mercantil, relativos ao anno de 1930, para ser apresentado em Assembléia Geral de Accionistas no dia 27 de março de 1931. Diário Official de Alagoas. Maceió: Governo do Estado de Alagoas, 26 mar. 1931. p. 5. 
COMPANHIA UNIĀO MERCANTIL. Edital. Diário Oficial de Alagoas. Maceió: Governo do Estado de Alagoas, 27 mar. 1940. p.10.

ENSINO. Correio da Manhä, Maceió, 2. a caderno, p. 7, 16 mar. 1958.

FARIAS, Ivo dos Santos. Nossa casa é do patrão: dominação e resistência operária no núcleo fabril de Fernão Velho, Maceió, AL. Curitiba: Appris, 2014.

FERREIRA, Veríssimo. História de Fernão Velho. Maceió: [s.n.], 1997. Mimeografado.

GUIMARÁES NETO, Regina Beatriz. Historiografia, diversidade e história oral: questôes metodológicas. In: LAVERD, Robson et al (Org.). História oral, desigualdade e diferenças. Recife: Editora Universitária da UFPE; Editora UFSC, 2012. p. 15-37.

MARROQUIM, Adalberto. Terra das Alagoas. Maceió: Grupo Joáo Lyra, 2000. Ediçáa fac-similar.

MEMÓRIA da vida e do trabalho. Direção e produção: Celso Brandão. Roteiro: Regina Coeli. Argumento e texto: José Sérgio Leite Lopes e Rosilene Alvim. Documentário. Maceió: Estrela do Norte, 1986. 1 DVD (20 min), son., color.

MONTENEGRO, Antonio Torres. Percursos historiográficos e metodológicos da contemporaneidade. In: SANTHIAGO, Ricardo; MAGALHÃES, Valéria Barbosa de (Org.). Depois da utopia: a história oral em seu tempo. São Paulo: Letra e Voz, 2013. p. 69-70.

PORFÍRIO, Pablo. Medo, comunismo e revolução: Pernambuco, 1959-1964. Recife: EdUFPE, 2009.

RICOEUR, Paul. História/epistemologia. In: - A memória, a história, o esquecimento. Campinas: Editora da Unicamp, 2007a. p. 143-296.

. O esquecimento. In:

Editora da Unicamp, 2007b. p. 423-466.

A memória, a história, o esquecimento. Campinas:

RODEGHERO, Carla Simone. O diabo é vermelho: imaginário anticomunista e Igreja Católica no Rio Grande do Sul, 1945-1964. Passo Fundo: Editora Universitária UPF, 2003.

SAVAGE, Mike. Classe e história do trabalho. In: BATALHA, Claudio Henrique de Moraes; SILVA, Fernando Teixeira da; FORTES, Alexandre (Org.). Culturas de classe. Campinas: Editora da Unicamp, 2004. p. 25-48. 
SIRINELLI, Jean-François. A geração. In: FERREIA, Marieta de Moraes; AMADO, Janaína. (Org.). Usos \& abusos da História Oral. Rio de Janeiro: Editora FGV, 2002. p. 131-137.

TAVARES, Marcelo Góes. Do tecer da memória ao tecido da história: operários, trabalho e política na indústria têxtil de Fernão Velho (1943-1961). Tese (Doutorado em História) - UFPE, Recife, PE, 2016.

THOMPSON, Edward Palmer. A miséria da teoria ou um planetário de erros: uma crítica ao pensamento de Althusser. Rio de Janeiro: Zahar, 1981.

As peculiaridades dos ingleses. In: NEGRO, Antonio Luigi; SILVA, Sergio (Org.). E. P. Thompson: as peculiaridades dos ingleses e outros artigos. Campinas: Editora da Unicamp, 1998.

\section{Fontes orais}

CARDOSO, Antônio [77 anos]. [set. 2015]. Entrevistador: Marcelo Góes Tavares, Maceió, AL, 15 set. 2015.

IDELBRANDO [82 anos]. [jan. 2014]. Entrevistador: Marcelo Góes Tavares, Maceió, AL, 18 jan. 2014.

NETTO, José Accioly (Zequinha Moura) [78 anos]. [jan. 2014]. Entrevistador: Marcelo Góes Tavares, Maceió, AL, 23 jan. 2014.

SOUZA, Emília de [79 anos] [set. 2014]. Entrevistador: Marcelo Góes Tavares, Maceió, AL, 30 set. 2014.

Resumo: Este artigo narra a experiência histórica da cultura operária no ramo têxtil em Fernão Velho, Maceió (AL). Essa localidade é parte de um território formado pela Fábrica Carmen e sua vila operária. Dessa forma, sãos recuperadas historicamente experiências operárias com foco no cotidiano. Narra-se a iniciação e desenvolvimento do trabalho fabril entre jovens, a constituição de famílias, formas de lazer, educação e formaçấo moral, tudo como expressōes de cultura de classe. Como corpus documental, são utilizados relatos de memórias registrados através da metodologia da História Oral, relatórios da fábrica, fotografias, e matérias de jornais. As análises apresentadas transitam entre estudos sobre História e Memória, experiência, poder, cotidiano e cultura de classe.

Palavras-chave: História. Memória operária. Cultura de classe. Cotidiano. Fernão Velho. Fábrica Carmen. 
Histories and memories of textile workers: scenes of factory culture and daily in Fernáo Velho - AL (1930s - 1960s)

Abstract: This article narrates the historical experience of worker culture in the textile industry in Fernão Velho, Maceió (AL). This locality is part of a territory formed by Carmen Factory and its worker village. In this way, workers' experiences with a focus on daily life are historically recovered. The initiation and development of factory work among young people, the constitution of their families, forms of leisure, education and moral training are narrated, all as expressions of class culture. As documentary corpus, reports of memories recorded using the methodology of Oral History, factory reports, photographs, and newspaper articles are used. The analyzes presented go through studies on History and Memory, experience, power, daily life and class culture.

Keywords: History. Worker memory. Class culture. Daily. Fernão Velho. Carmen Factory.

Recebido em 22/08/20

Aprovado em 21/10/20 